\title{
Snow gliding and glide-snow avalanches: recent outcomes from two experimental test sites in Aosta Valley (northwestern Italian Alps)
}

\author{
Margherita Maggioni ${ }^{1,2}$, Danilo Godone ${ }^{2,3}$, Barbara Frigo ${ }^{4}$, and Michele Freppaz ${ }^{1,2}$ \\ ${ }^{1}$ DISAFA, University of Turin, Grugliasco (TO), 10095, Italy \\ ${ }^{2}$ NatRisk, University of Turin, Grugliasco (TO), 10095, Italy \\ ${ }^{3}$ IRPI, National Research Council, Turin, 10135, Italy \\ ${ }^{4}$ DISEG, Politecnico di Torino, Turin, 10129, Italy
}

Correspondence: Margherita Maggioni (margherita.maggioni@unito.it)

Received: 6 April 2019 - Discussion started: 22 May 2019

Revised: 10 September 2019 - Accepted: 24 October 2019 - Published: 28 November 2019

\begin{abstract}
Snow gliding and glide-snow avalanches are gaining importance among scientists as global warming might induce conditions favourable to those phenomena. Our aim is to analyse such processes with a particular focus on the potential driving factors associated with the soil conditions. We equipped two experimental test sites in the Aosta Valley region (NW Italy) with glide-snow shoes, temperature and volumetric liquid water content (VLWC) sensors in the soil and in the basal snowpack layer; snow and weather parameters were also collected by automatic weather stations and at manual snow measuring sites.

In the two monitoring seasons 2013-2014 and 2014 2015 we registered nine glide-snow avalanches, two cold and seven warm events, which were characterized by different snow and soil conditions. In the only warm glide-snow avalanche event, which presented a continuous gliding before, the daily glide rate showed a significant exponential relationship with the soil VLWC. We also found, though without a general trend, that gliding and non-gliding periods (either considering warm and cold periods separately or together) were characterized by significantly different predisposing factors.

This study contributes to the assessment of the importance of soil VLWC, which seems to be one of the most important driving factors for gliding processes. Therefore, it supports the need, already suggested by other scientists, for analysing such processes with an interdisciplinary approach which integrates snow and soil sciences.
\end{abstract}

\section{Introduction}

Snow gliding processes have recently gained importance among scientists as climate change might influence the snow cover and the related processes, leading to a reduction of dry snowpacks and an increase in wet ones (Castebrunet et al., 2014). Already in the past, scientists have studied snow gliding and glide-snow avalanches - see review papers by Höller (2014) and Ancey and Bain (2015) - but current and future climate change might generate scenarios prone to such processes; therefore they are again gaining importance. In fact, increase in the air temperature and in the snowfall limit (Hartmann et al., 2013) may influence the snow cover, which might become denser and wetter, also due to more frequent rain on snow events, in particular close to $2000 \mathrm{~m}$ a.s.l. (Morán-Tejeda et al., 2016).

A deep knowledge of the most important driving factors of such phenomena deserves attention, in order to be able to eventually predict and manage them in the optimum way. Already In der Gand and Zupancic (1966) state that snow gliding occurs on a smooth ground surface, a lowermost layer of wet snow and a temperature at the snow-ground interface of $0{ }^{\circ} \mathrm{C}$. Based on different driving factors, some scientists elaborated models to predict snow gliding distances (e.g. Leitinger et al., 2008) or to identify areas prone to snow gliding (e.g. Maggioni et al., 2016).

The approach commonly used for studying snow gliding and glide-snow avalanches starts from the distinction between cold and warm temperature events (Clarke and McClung, 1999). This distinction is based on the origin of liquid water at the snow-soil interface: in a cold event, the nec- 
essary wet snow-soil interface originates either from snow melting at basal layers of the snowpack or from water suction from the soil; in a warm event, the water originates from melting processes at the snow surface, percolates through the snowpack and ponds at the snow-soil interface. However, Margueritat (2016) recently registered cases of snow gliding in wintertime (cold events) without a basal layer of wet ground grains, but in certain cases with a basal layer made of faceted particles.

The most recent studies by Ceaglio et al. (2017) and Fromm et al. (2018) underline the importance of soil moisture as a driving factor for snow gliding. In particular, Ceaglio et al. (2017) found a strong relation between glidesnow rate and moisture at the snow-soil interface for cold temperature events, also with a possible contribution of soil liquefaction, while Fromm et al. (2018) found that soil moisture and temperature had a significant influence on snow gliding in both warm and cold periods.

As in Ceaglio et al. (2017) and Fromm et al. (2018), this work, using an experimental approach, starts from data gathered at two test sites and aims at giving a contribution to the ongoing scientific discussion on the most important driving factors for snow gliding and glide-snow avalanches. Our goal is to quantify the linkages between soil water content and snow gliding processes and to assess the factors predisposing the glide avalanche release, under different meteorological and snowpack conditions (warm vs. cold events).

\section{Data and methods}

\subsection{Study area}

The study area is located within the MonterosaSki resort in the NE of the Aosta Valley region (NW Italian Alps), in the Monte Rosa massif, close to the LTER site Istituto Mosso (https://deims.org/17210eba-d832-4759-89fa-9ff127cbdf6e, last access: 21 November 2019). From the data taken at the weather station Gressoney-L.T. (1837 ma.s.l.), which has the longest time series among the different weather stations present in the area (Fig. 1a), the long-term mean precipitation (including the snow water equivalent) is $1111 \mathrm{~mm} \mathrm{yr}^{-1}$ (1927-2017), the mean annual air temperature is $4.2^{\circ} \mathrm{C}$ (1971-2017) and the average cumulative snowfall is $398 \mathrm{~cm}$ (1981-2010).

Two test sites were equipped in the study area for measuring snow gliding and snow and soil properties (Fig. 1b). The site "Pista Nera" is a slope at about $2230 \mathrm{~m}$ a.s.l. with an average inclination of $40^{\circ}$ with an ESE aspect. The soil is classified as Cambisol and is characterized by a liquid limit (LL) in the topsoil $(0-10 \mathrm{~cm}$ depth) and in the underlying soil horizon (10-20 cm depth) equal to $53 \%$ and $47 \%$, respectively. The slope is covered by a mountain grassland (Festuca scabriculmis) with sparsely low dwarf shrubs (Juniperus nana, Calluna vulgaris and Rhododendron ferrug-
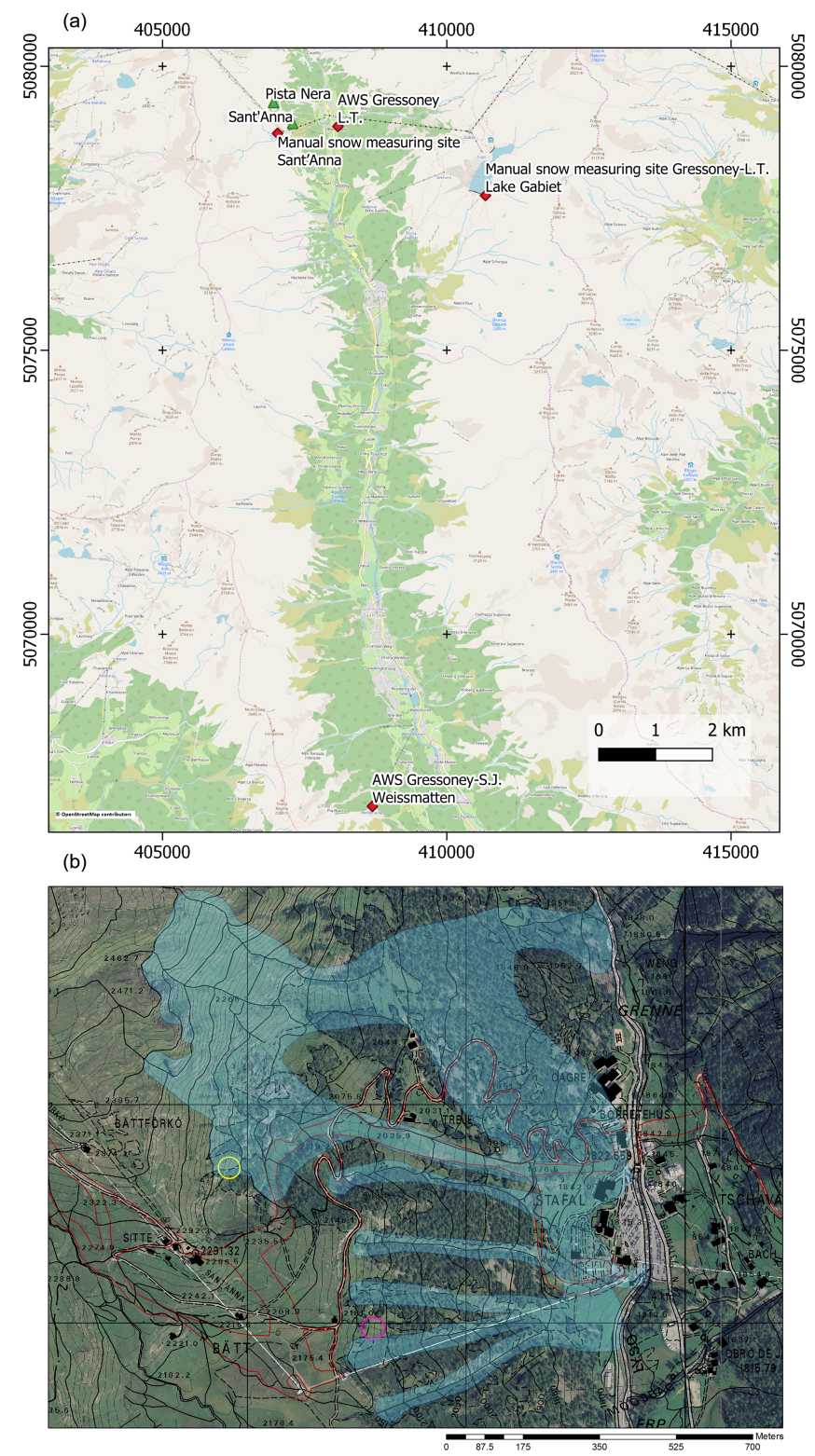

Figure 1. (a) Location of the two test sites (green triangles), the automatic weather stations and the manual snow measuring sites (red diamonds). Source: https://www.openstreetmap.org/copyright. (C) OpenStreetMap contributors 2019. Distributed under a Creative Commons BY-SA License. (b) Location of the two test sites "Pista Nera" and "Sant'Anna", shown with the yellow and pink circles (in red the ski runs of the MonterosaSki resort are reported, while the light blue polygons represent the perimeter of the maximum avalanche events registered in the Avalanche Cadastre of the Aosta Valley region).

ineus). The site "Sant' Anna" is a slope at about $2120 \mathrm{~m}$ a.s.l. with an average inclination of $36^{\circ}$ with an east aspect. The soil is classified as Regosol, with a liquid limit of $84 \%$ and $76 \%$ in the topsoil and in the underlying soil horizon, respectively. The dominant plant species are Festuca rubra s.l. and 


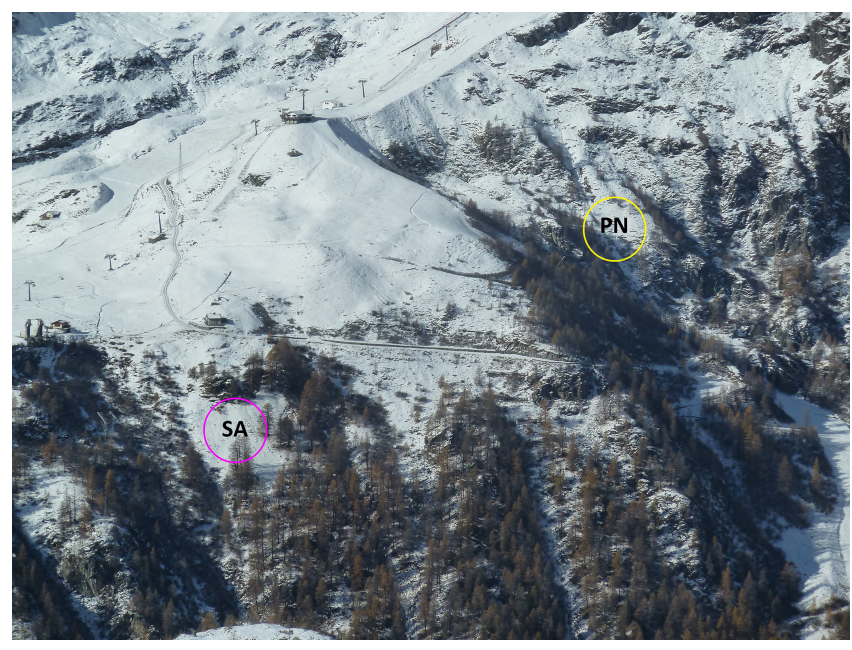

Figure 2. Winter view of the study area: in the circles the location of the two test sites Pista Nera (PN) and Sant'Anna (SA) is shown.

Agrostis tenuis. The glide-snow avalanches released from the Pista Nera site can reach the ski run below (Figs. 1b and 2) and therefore need a careful monitoring.

\subsection{Data collection}

The data were collected during the hydrological years 20132014 and 2014-2015. Snow and meteorological parameters (snow depth, precipitation, air temperature, and wind speed and direction) were provided by the automatic weather station (AWS) "Gressoney-S.J. - Weissmatten", which has been operational since 2002 and is placed $12 \mathrm{~km}$ further south from the study site at $2038 \mathrm{~m}$ a.s.l. (Fig. 1a). The new snow amount in $24 \mathrm{~h}$ was gathered from the manual snow measuring site Gressoney-L.T. - Lake Gabiet (2370 m a.s.1.) $4 \mathrm{~km}$ east from the study sites (Fig. 1a). These two stations are considered representative of the snow and weather conditions for the study site. In particular, we realized from previous analysis how the time of evolution of the snow depth for the study site is similar to that measured at Gressoney-S.J. - Weissmatten.

To describe the physical properties of the snowpack, we used the weekly snow profiles made at the manual snow measuring site Sant'Anna, very close (less than $1 \mathrm{~km}$ ) to the study sites (Fig. 1a), by the Corpo Forestale Valdostano (forestry office). Moreover, after specific gliding events, we performed ad hoc snow surveys at the study sites. Observations were performed according to Fierz et al. (2009).

At the two test sites, instrumentation was installed for measuring snow gliding and snow and soil properties (Fig. 3). At each test site, two glide-snow shoes, connected to potentiometers $\left(\right.$ Sommer $^{\circledR}$ ), were placed within the area where glide cracks were observed in the past. In addition to the glide-snow shoes, temperature sensors (Campbell 107 temperature probe) and volumetric liquid water con-

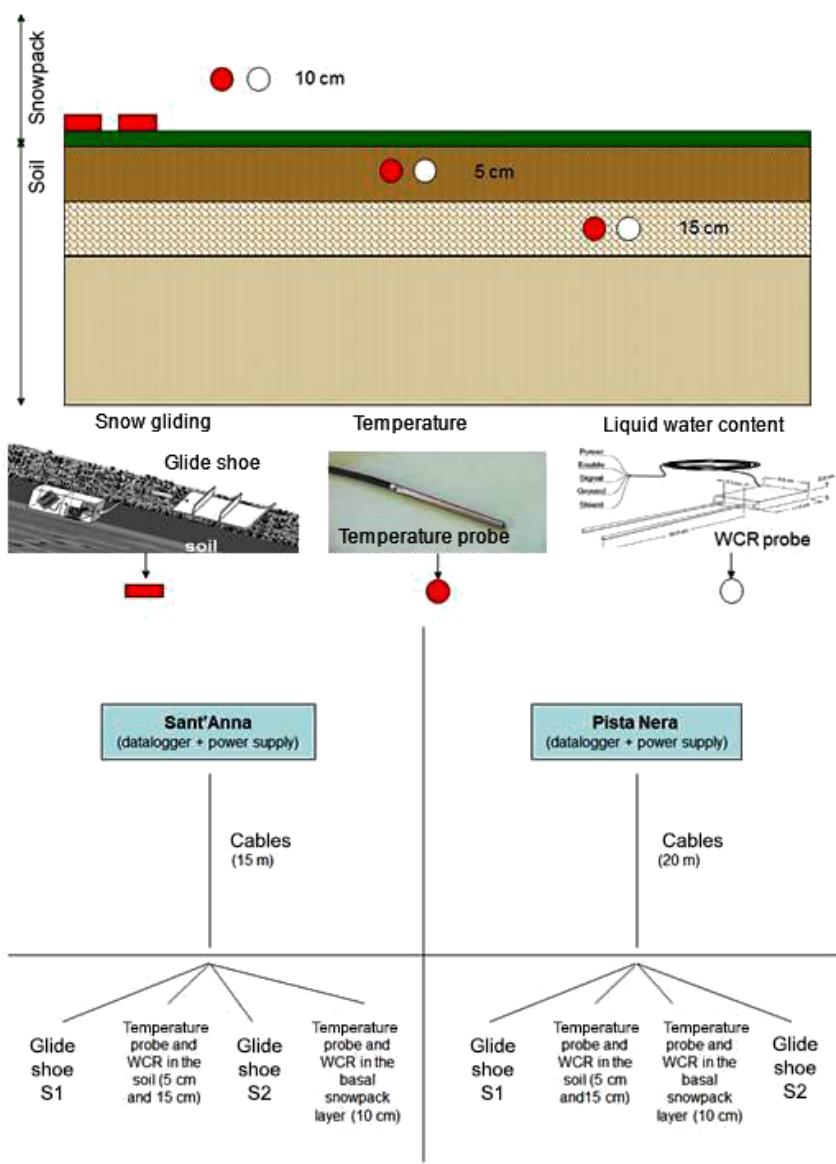

Figure 3. Set-up of the experimental test sites.

tent probes (Campbell-CS616 - water content reflectometers, WCRs) were placed in the basal layer of the snowpack and at two different soil depths ( 5 and $15 \mathrm{~cm}$ ). The scheme of the instrumental set-up for both sites is given in Fig. 3. Moreover, a webcam was continuously monitoring the possible glide crack formation and evolution at the Pista Nera site.

The manager of the ski area security monitored the specific conditions at the study sites: for example, when a glide avalanche occurred, he informed us so that we could record the characteristics of the event and reset the instrumentation. The reset of the instrumentation consisted in checking the positions of the temperature sensors and the WCR probes and, when possible in terms of safety standards, in repositioning the glide shoes involved in the avalanche.

\subsection{Data analysis}

During the two monitoring seasons, we selected different periods for the analyses of the data registered by each single glide shoe at the two test sites (Table 1). In fact, the four glide shoes showed different patterns (see later in Sect. 3). Moreover, the periods for the analyses were also chosen according to the specific snow conditions observed at the sites, 
Table 1. Periods of analyses for each single glide shoe at the two test sites during the two monitoring seasons. Dates are in day/month/year; $N$ indicates the number of data in the corresponding period.

\begin{tabular}{lllr}
\hline Period & Glide-snow shoe & Cold/warm & $N$ \\
\hline Pista Nera & & & \\
\hline $31 / 10-21 / 11 / 2013$ & S1 and S2 & cold & 22 \\
$19 / 12 / 2013-6 / 03 / 2014$ & S1 and S2 & cold & 78 \\
$7-18 / 03 / 2014$ & S1 and S2 & warm & 12 \\
$23-28 / 03 / 2014$ & S1 and S2 & warm & 6 \\
$19-22 / 04 / 2014$ & S1 and S2 & warm & 4 \\
$27-29 / 04 / 2014$ & S1 and S2 & warm & 3 \\
$28 / 10-8 / 11 / 2014$ & S1 and S2 & warm & 12 \\
$9-12 / 11 / 2014$ & S2 & warm & 4 \\
\hline Sant'Anna & & & \\
\hline $31 / 10-24 / 11 / 2013$ & S1 and S2 & cold & 25 \\
$19 / 12 / 2013-6 / 03 / 2014$ & S1 and S2 & cold & 78 \\
$7 / 03-09 / 05 / 2014$ & S1 and S2 & warm & 64 \\
$28 / 10-13 / 11 / 2014$ & S1 and S2 & warm & 17 \\
$15-30 / 11 / 2014$ & S1 and S2 & warm & 16 \\
$1-24 / 12 / 2014$ & S2 & warm & 24 \\
$25 / 12 / 2014-6 / 03 / 2015$ & S2 & cold & 72 \\
$7 / 03-22 / 04 / 2015$ & S2 & warm & 47 \\
\hline
\end{tabular}

which influenced the significance of the registered temperature and volumetric liquid content (VLWC) parameters. For example, after a glide avalanche event, identified as a large sudden glide shoe movement and/or from field survey, the instrumentation was reset but the site remained with no snow until the next snowfall; therefore this period could not be considered for analysis. In periods of no analyses the data registered by the WCR probe in the basal snowpack layer might show unrealistic values.

We considered daily values, which were obtained by averaging the $30 \mathrm{~min}$ values for all parameters, except for the daily glide-snow rate, which was calculated as the difference of the cumulative gliding at 23:30 local time between two consecutive days.

As WCR probes were mainly designed to measure volumetric liquid water content in soils, we were able to transform the values recorded by the instrument place in the basal snowpack layer following the corrections found by Godio et al. (2018) during an experimental campaign carried out at the vicinity of the manual measuring site of Sant'Anna.

We performed statistical analyses to investigate the difference between cold and warm gliding events in terms of driving factors (snow and soil and VLWC, air temperature, snow height, new snow in $24 \mathrm{~h}$ ). We assume that the distinction between a cold and a warm temperature event is related to the origin of the liquid water at the snow-soil interface as in Ceaglio et al. (2017).
Concerning glide-snow avalanche events, we explore possible differences between driving factors measured at the moment of the events (semi-hourly data) for warm and cold events, applying the Wilcoxon-Mann-Whitney test.

We executed univariate (Mann-Whitney $U$ test) and multivariate (classification trees) statistical analyses to explore differences between periods of gliding (identified as those days with a daily glide rate greater than $0.5 \mathrm{~cm} \mathrm{~d}^{-1}$ for at least one glide shoe) and periods of no gliding. Initially, we considered the whole dataset at once and then we classified into cold and warm periods at the two test sites, in order to investigate the potential differences in the driving factors.

We also checked potential relationships between glide rate and soil VLWC.

In addition to the above-mentioned quantitative analyses, we also made a qualitative description of the two monitoring seasons, trying to explain some patterns found in the registered values for specific days.

\section{Results and discussion}

\subsection{Predisposing factor for glide avalanche events}

Figures 4-7 report the pattern of the registered variables along the two monitoring seasons at the two test sites. In total, we registered nine glide-snow avalanches. Other events occurred during the first season but were only observed through field surveys without measurements by the glidesnow shoes. Among the measured events, two have been classified as cold events and seven as warm events (among which one was related to a rain-on-snow episode). Often the events occurred suddenly without appreciable snow gliding before.

The two cold glide-snow avalanche events were recorded in late autumn 2013 at both sites, while the warm events were recorded in both autumn and spring. In the literature (e.g. Dreier et al., 2016), cold events were usually associated with the beginning of the winter season, while warm ones were only associated with the end. But the beginning of season 2014-2015 was meteorologically an exception. In fact, November 2014 was the second warmest (air temperature $3.1^{\circ} \mathrm{C}$ above the average) and the rainiest ( $378 \%$ more than the average) November of the previous 57 years in the NW Italian region (ARPA Piemonte, 2015). The conditions were not typically winter; the first available snow profile (17 December) described a wet snowpack with melt forms in the basal layer. We classified the registered gliding events that occurred in November 2014 as warm; on 30 November a glide avalanche due to a rain-on-snow (ROS) event occurred. For such events soil VLWC was around 35\% in Sant'Anna, while in Pista Nera it started around $15 \%$ (5 November) and increased to $22 \%$ on 30 November. The soil was not frozen at both sites. In comparison to 2013-2014 the soil showed the same values of VLWC in Sant'Anna, while in Pista Nera the 

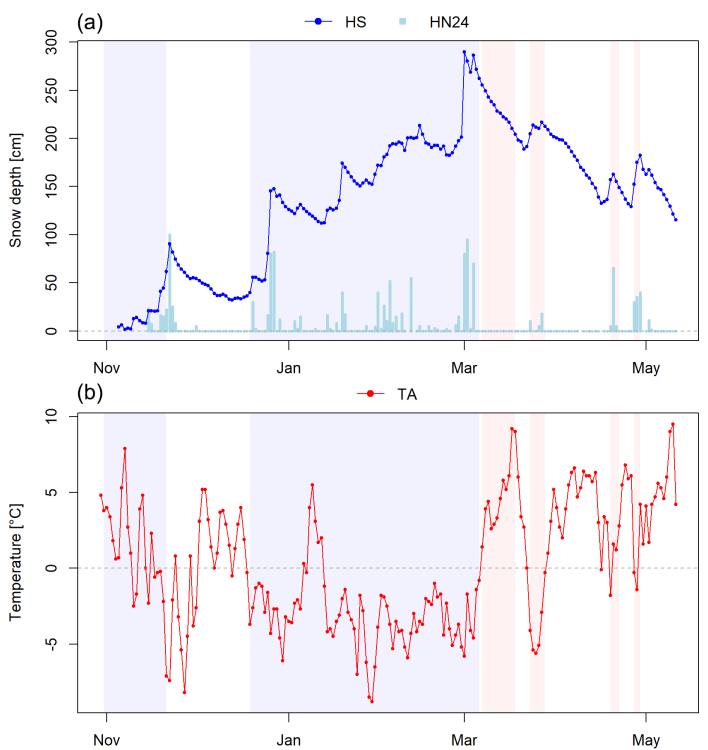

$\begin{array}{ll}\text { Nov } & \text { Jan } \\ \text { (c) } & -5 \mathrm{~cm}-15 \mathrm{~cm}\end{array}$

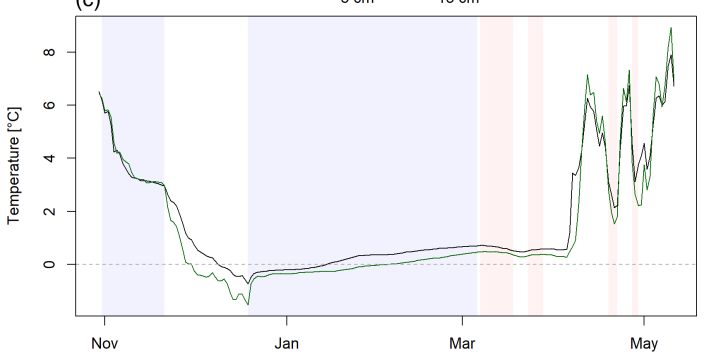

(d)

$-15 \mathrm{~cm}-5 \mathrm{~cm} *$ Snow

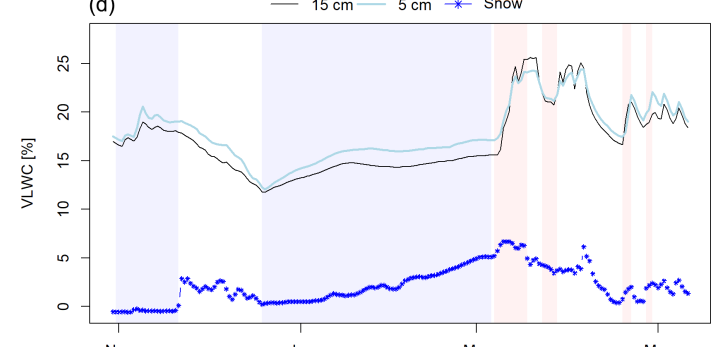

Nov Jan Mar May

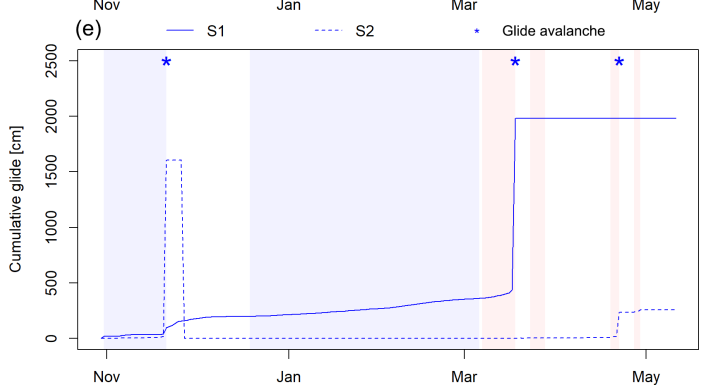

Figure 4. Site Pista Nera, winter season 2013-2014: (a) snow depth (HS) from AWS Weissmatten and new snow sum (HN24) from the manual snow measuring site Gabiet, (b) air temperature (TA) from AWS Weissmatten, (c) soil temperature, (d) VLWC measured within the soil and in the basal snowpack layer, (e) cumulative glide. Warm and cold periods are highlighted in orange and blue, respectively; periods reported in white are periods of no data analyses for S1, S2 or both (see Table 1 for details).
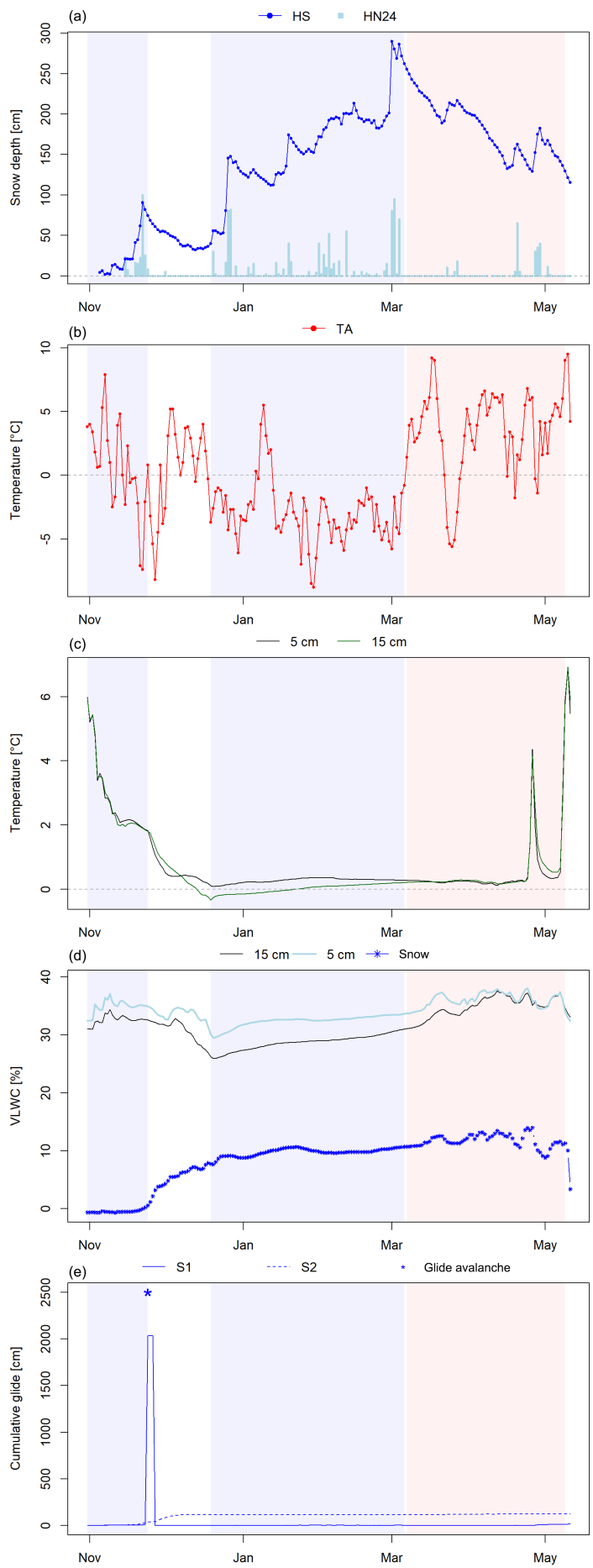

Figure 5. Site Sant'Anna, winter season 2013-2014: (a) snow depth (HS) from AWS Weissmatten and new snow sum (HN24) from manual snow measuring site Gabiet, (b) air temperature (TA) from AWS Weissmatten, (c) soil temperature, (d) VLWC measured within the soil and in the basal snowpack layer, (e) cumulative glide. Warm and cold periods are highlighted in orange and blue, respectively; periods reported in white are periods of no data analyses for $\mathrm{S} 1, \mathrm{~S} 2$ or both (see Table 1 for details). 

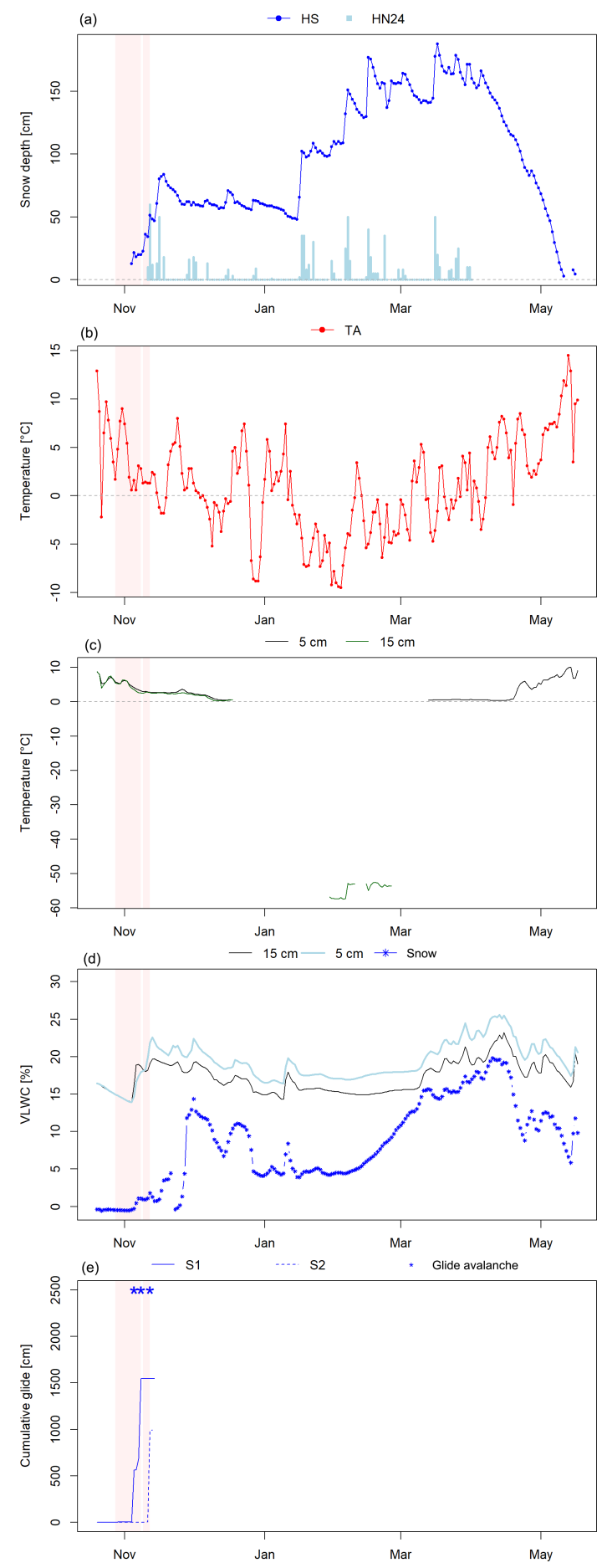

Figure 6. Site Pista Nera, winter season 2014-2015: (a) snow depth (HS) from AWS Weissmatten and new snow sum (HN24) from manual snow measuring site Gabiet, (b) air temperature (TA) from AWS Weissmatten, (c) soil temperature, (d) VLWC measured within the soil and in the basal snowpack layer, (e) cumulative glide. Warm and cold periods are highlighted in orange and blue, respectively; periods reported in white are periods of no data analyses for S1, S2 or both (see Table 1 for details) (the period 9-12 November 2014 has no analyses for S1). In periods of no analyses the data registered by the WCR probe in the basal snowpack layer might show unrealistic values.
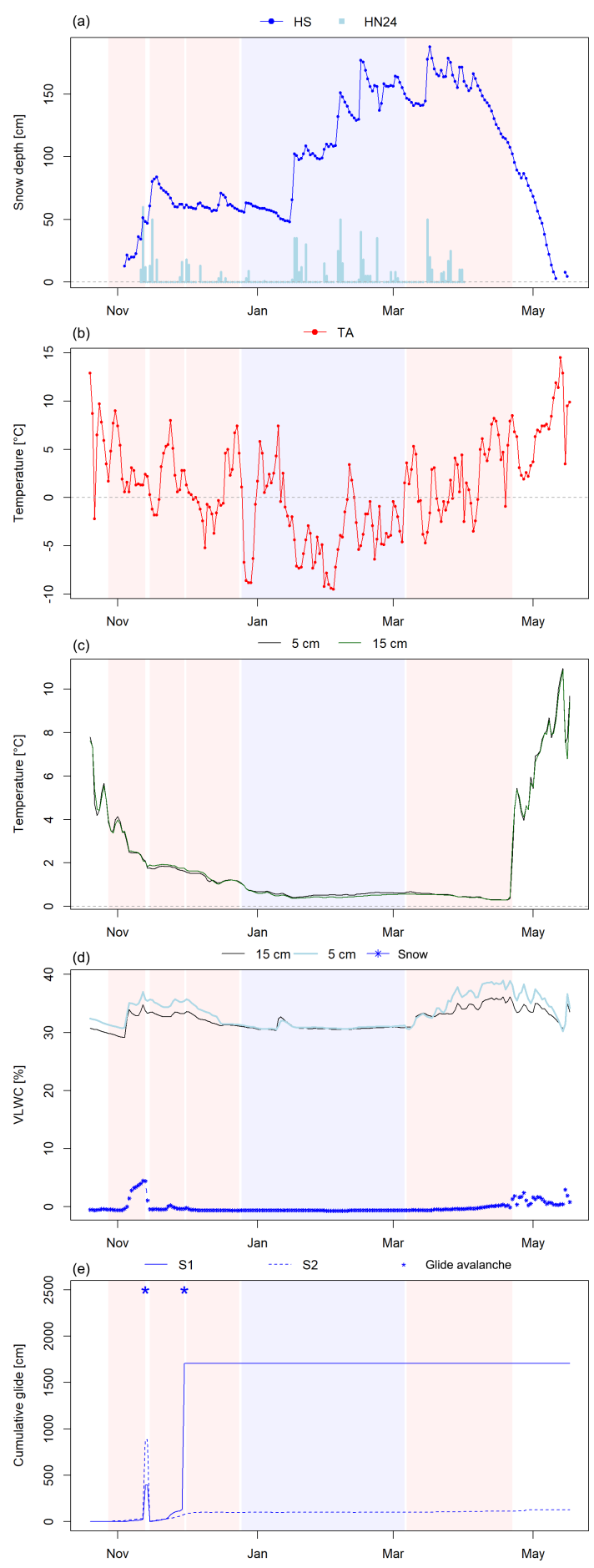

Figure 7. Site Sant'Anna, winter season 2014-2015: (a) snow depth (HS) from AWS Weissmatten and new snow sum (HN24) from manual snow measuring site Gabiet, (b) air temperature (TA) from AWS Weissmatten, (c) soil temperature, (d) VLWC measured within the soil and in the basal snowpack layer, (e) cumulative glide. Warm and cold periods are highlighted in orange and blue, respectively; periods reported in white are periods of no data analyses for S1, S2 or both (see Table 1 for details) (from 1 December 2014 to the end of the season there are no analyses for S1). 
soil was wetter in November 2014 than in November 2013. Soil in Sant' Anna was in general wetter than in Pista Nera in both seasons.

Analysing the patterns of air temperature and snow height, we could appreciate the fact that the warm events often occurred after a snowfall followed by an increase in air temperature, resulting in a decrease in the snow depth. This clearly occurred for the event in March 2014 in Pista Nera (Fig. 4). For warm events this might describe the situation in which snow melting occurred at the snow surface with percolating water through the snowpack down to the snow-soil interface with a lowering of the basal friction. The same occurred for the cold events in November 2013 at both sites, but with a less sharp decrease in the snow depth.

Comparing Sant'Anna and Pista Nera after the first snowfall at the end of November 2013, it is interesting to notice how this snowfall caused a snow gliding phenomenon at the Pista Nera site earlier than at Sant'Anna. In Pista Nera a glide avalanche occurred on 21 November, while in Sant'Anna one occurred on 24 November. From the analysis of the collected data, soil temperature in Pista Nera $\left(2.9^{\circ} \mathrm{C}\right)$ was $1{ }^{\circ} \mathrm{C}$ warmer than in Sant'Anna $\left(1.8^{\circ} \mathrm{C}\right)$, while soil moisture in Pista Nera (19\%) was about half that in Sant'Anna (35\%). Probably, the reason for the earlier movement in Pista Nera than in Sant'Anna lies in the average inclination of the sites, which is $40^{\circ}$ for Pista Nera and $36^{\circ}$ for Sant' Anna, and in the vegetation characteristics. Vegetation in Pista Nera is more favourable for gliding than that in Sant'Anna: though there are sparse lignified shrubs, Pista Nera presents longer grass, not grazed, while Sant' Anna is usually grazed by dairy cows. The differences in inclination and vegetation between the sites might also explain why in March 2014 the combination of a snowfall followed by an increase in air temperature produced a glide avalanche only in Pista Nera and not in Sant'Anna. However, despite some differences between the two sites, they both belong to classes which present a low basal friction, favourable for snow gliding (Feistl et al., 2014).

The complexity of the experimental test sites, with couples of glide shoes which behaved differently, could give us the possibility of trying to explain some differences between the glide shoes.

For example, at the beginning of the 2013-2014 season, in Pista Nera a glide avalanche occurred on 21 November involving glide shoe S2 in its movement (Fig. 4). This avalanche occurred after the first consistent snowfall of more than $1 \mathrm{~m}$ of new snow (Fig. 4). After this first event, no snowfall occurred until 19 December when $30 \mathrm{~cm}$ of new snow fell again. Glide shoe S2, which was reset on 27 November, did not move anymore until the last small and fast movement in April 2014. The data of soil temperature and moisture showed that the soil remained frozen until 14 January. The instruments were closer to $\mathrm{S} 2$ than $\mathrm{S} 1$, then representing the situation of no (or little, i.e. $30 \mathrm{~cm}$ from the snowfall on 19 December) snow on the ground between the event
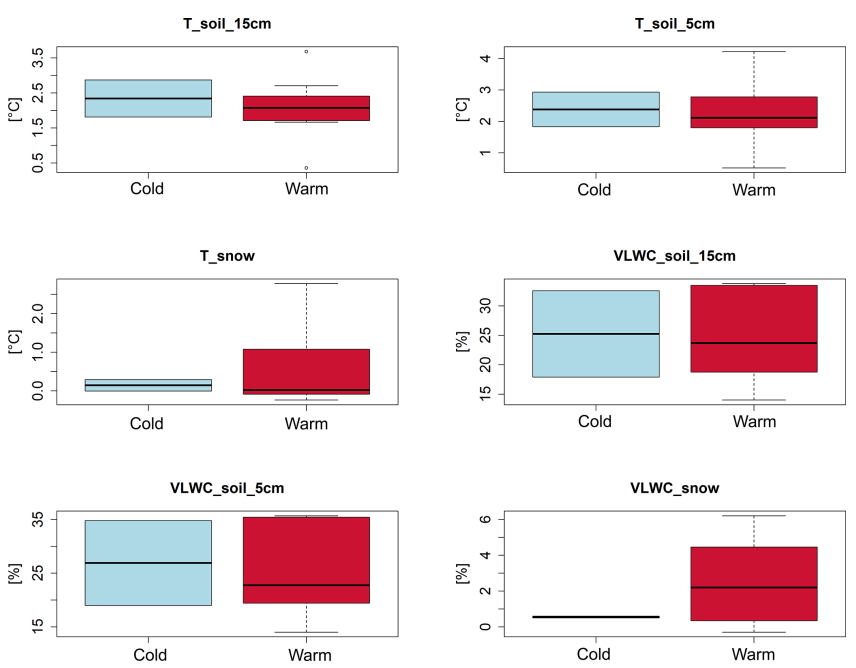

Figure 8. Box plots of the parameters registered at the moment of the cold and warm glide-snow avalanche events (values registered $30 \mathrm{~min}$ before the events).

on 21 November (which denudated the soil) and 14 January. Therefore, after the event on 21 November, S2 did not move because one of the necessary conditions for gliding was not present (snow-soil interface at $0^{\circ} \mathrm{C}$ ). Instead S1, which was not involved in the glide avalanche of 21 November, remained below $1 \mathrm{~m}$ of snow plus $30 \mathrm{~cm}$ from the snowfall on 19 December, when it started moving again continuously. At the location of $\mathrm{S} 1$ the snow on the ground was more than $1 \mathrm{~m}$ and possibly the soil was not frozen, favouring a continuous and gradual snow gliding, as registered by $\mathrm{S} 1$.

Simple descriptive statistics of the variables registered at the moment of the glide avalanche events (box plots in Fig. 8) showed that the cold glide-snow avalanche events were characterized, on average, by (i) a slightly higher soil VLWC $(26.9 \%$ and $25.3 \%)$ than in warm events $(25.6 \%$ and $24.9 \%$ ) at 5 and $15 \mathrm{~cm}$ depths, respectively; (ii) a lower VLWC $(0.6 \%)$ in the snowpack basal layer than in warm events $(2.5 \%)$; (iii) a slightly higher soil temperature at 5 and $15 \mathrm{~cm}$ depths (difference of 0.1 and $0.3^{\circ} \mathrm{C}$, respectively) than in warm events. Though it seems that there exist some little differences between the predisposing factors registered at the moment of the cold and warm glide-snow avalanche events, the differences are not statistically significant (WilcoxonMann-Whitney test). The fact that in cold events, registered at the beginning of the season, soil temperatures were higher than in warm events might be explained by the heat stored by the soil during the summer; while for the warm events in late spring the longer presence of the snowpack did not allow the soil to warm up and soil temperatures remained lower. Minor VLWC values in the basal snowpack layer during cold events represent the fact that the snow cover was cold, being formed by the first probably cold and dry snowfalls, while in spring the VLWC of the basal layer of the snow cover is the result 
of percolating water from above layers (the available water is more than that of cold snowpack at the beginning of the season). For the warm events at the beginning of the 2014-2015 season, the VLWC in the snow was related to the melting of the first snowfalls that occurred in November with warm air temperature (see Figs. 6 and 7).

\subsection{Gliding vs. non-gliding periods}

In Sant'Anna and Pista Nera the differences between gliding and non-gliding periods in terms of the measured parameters (Tables 2 and 3) were highly significant when considering the whole dataset together, while in Pista Nera significant differences were found only in cold periods and in Sant'Anna only in warm periods. Some differences could be reasonably explained by what we think the snow gliding process is, also according to existing literature (e.g. Höller, 2014 and Ancey and Bain, 2015), while others are difficult to understand. For example, in Pista Nera the VLWC in the snow was significantly higher for gliding than for non-gliding periods when considering the whole dataset or cold periods. This was also found by Fromm et al. (2018) and Ceaglio et al. (2017). Instead, in Sant'Anna there was no difference in the VLWC of snow during cold periods; a little significant difference was found in warm periods, but the VLWC of snow was higher in non-gliding than in gliding periods, revealing how other predisposing factors could contribute to the snow gliding process.

The multivariate CART analyses produced results, for the whole dataset or dividing warm and cold periods, which show how different variables (e.g. air temperature, soil temperature and VLWC) appear in the decision process (splitting nodes) but without a general trend.

\subsection{Predisposing factors for snow gliding}

In Pista Nera for the warm gliding periods at the end of the season, the daily glide rate showed a significant $(p<0.001)$ exponential relationship with the soil VLWC at both depths (Fig. 9). Conversely, we did not find any relationship between the glide rate and the soil VLWC in the continuous cold gliding period in Pista Nera, as we have recently found at another experimental test site in the same region (Ceaglio et al., 2017). The difference between those findings and the results presented here might also be related to the soil properties of the two different test sites, in particular to the Atterberg liquid limits. The Atterberg liquid limits (LLs) represent the soil moisture content value determining the transition from the plastic to the liquid state (LL) (Lal and Shukla, 2004; Stanchi et al., 2012). The LL for the deeper soil horizon (10$20 \mathrm{~cm}$ depth) at the site of Mt de La Saxe (in Ceaglio et al., 2017) was around $48 \%-67 \%$, and the registered soil VLWC was around $50 \%$. In Pista Nera (where we registered a cold gliding period in 2013-2014 which did not show any relationship between the glide rate and the VLWC) the LL was

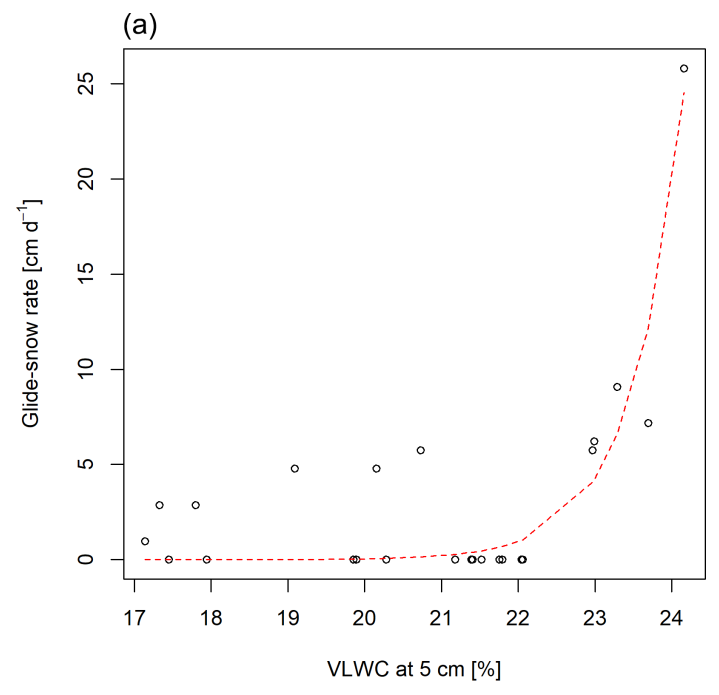

(b)

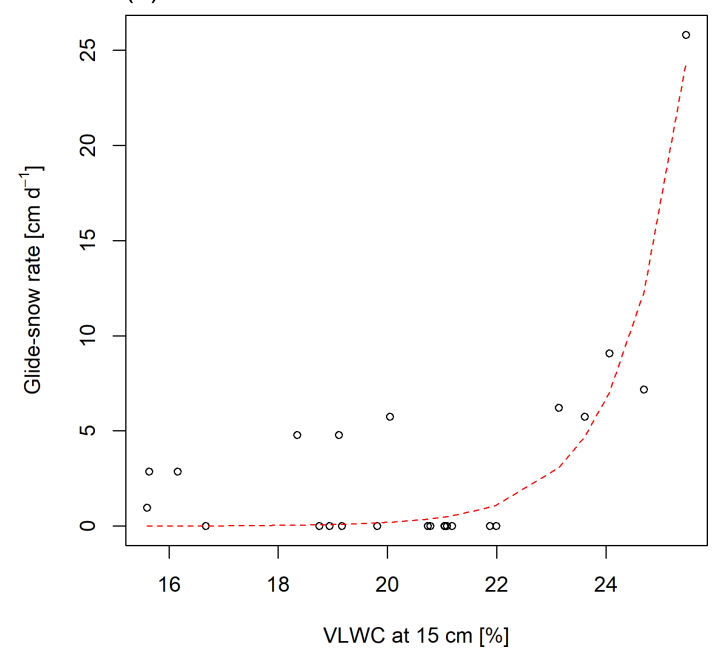

Figure 9. Fitting model between daily glide-snow rates for $\mathrm{S} 1$ and volumetric liquid water content (VLWC) measured in Pista Nera at $5 \mathrm{~cm}$ (a) and $15 \mathrm{~cm}$ (b) soil depths during the warm events of the 2014 season.

$53 \%$ (topsoil) and $47 \%$ (underlying horizon), values never measured by the WCR sensors (Fig. 4). In Mt de La Saxe soil liquefaction was possible (and actually observed in the field), while in Pista Nera this was not observed at all. Therefore, in Mt de La Saxe a further driving factor for snow gliding in cold periods might have been soil liquefaction, which did not occur in Pista Nera in 2014.

For Sant'Anna we did not find any relationship between the daily glide rate and the soil VLWC for both the identified warm and cold periods. 
Table 2. Pista Nera: summary statistics showing median values of various variables for gliding days (Gd) and non-gliding days (NonGd). For each variable, distributions were contrasted (Mann-Whitney $U$ test), and the level of significance $p$ is given. Temperatures are in degrees Celsius, VLWC is in percent and snow height is in centimetres.

\begin{tabular}{lrrr|rrr|r|rr}
\hline Variables & \multicolumn{3}{c|}{ All data } & \multicolumn{3}{c|}{ Cold periods } & \multicolumn{3}{c}{ Warm periods } \\
\cline { 2 - 10 } & Gd & NonGd & $p$ value & Gd & NonGd & $p$ value & Gd & NonGd & $p$ value \\
\hline T_snow & -0.19 & -0.22 & 0.173 & -0.2 & -0.2 & 0.684 & 0.75 & -0.22 & 0.354 \\
VLWC_snow & 1.8 & 0 & $<0.001^{* * *}$ & 1.81 & 0 & $<0.001^{* * *}$ & 1.8 & 3.57 & 0.585 \\
T_soil5cm & 0.55 & 3.13 & $0.022^{*}$ & 0.37 & 3.15 & $0.043^{*}$ & 2.7 & 0.58 & 0.288 \\
VLWC_soil5cm & 16.3 & 19.12 & 0.085 & 16.18 & 17.67 & 0.06 & 18.29 & 21.29 & 0.727 \\
T_soil15cm & 0.23 & 3.11 & $0.007^{* *}$ & -0.01 & 3.2 & $0.043^{*}$ & 2.21 & 0.38 & 0.202 \\
VLWC_soil15cm & 14.8 & 18.11 & $0.04^{*}$ & 14.65 & 17.26 & $0.048^{*}$ & 18.75 & 20.89 & 0.601 \\
TA & -1.9 & -0.8 & 0.291 & -2.9 & -0.3 & $0.001^{* *}$ & 2.8 & -2.15 & $0.009^{* *}$ \\
HN24 & 0 & 2.5 & 0.838 & 2 & 0 & 0.805 & 0 & 5 & 0.474 \\
HS & 157 & 56 & 0.084 & 156 & 21 & $<0.001^{* * *}$ & 163 & 212 & 0.394 \\
\hline
\end{tabular}

Table 3. Sant'Anna: summary statistics showing median values of various variables for gliding days (Gd) and non-gliding days (NonGd). For each variable, distributions were contrasted (Mann-Whitney $U$ test), and the level of significance $p$ is given. Temperatures are in degrees Celsius, VLWC is in percent and snow height is in centimetres.

\begin{tabular}{lrrr|rrr|rrr}
\hline \multirow{2}{*}{ Variables } & \multicolumn{3}{c}{ All data } & \multicolumn{3}{c|}{ Cold periods } & \multicolumn{3}{c}{ Warm periods } \\
\cline { 2 - 10 } & Gd & NonGd & $p$ value & Gd & NonGd & $p$ value & Gd & NonGd & $p$ value \\
\hline T_snow & -0.05 & -0.07 & $<0.001^{* * *}$ & -0.05 & -0.06 & 0.619 & -0.05 & -0.08 & $<0.001^{* * *}$ \\
VLWC_snow & -0.27 & 4.5 & 0.378 & -0.41 & -0.51 & 0.846 & -0.25 & 10.8 & $0.026^{*}$ \\
T_soil5cm & 0.6 & 0.38 & $<0.001^{* * *}$ & 0.53 & 0.44 & 0.1 & 0.64 & 0.31 & $<0.001^{* * *}$ \\
VLWC_soil5cm & 34.58 & 32.67 & $<0.001^{* * *}$ & 32.45 & 32.01 & 0.115 & 35.33 & 35.36 & 0.676 \\
T_soil15cm & 0.55 & 0.37 & $<0.001^{* * *}$ & 0.46 & 0.38 & 0.139 & 0.93 & 0.29 & $<0.001^{* * *}$ \\
VLWC_soil15cm & 32.86 & 30.88 & $<0.001^{* * *}$ & 30.75 & 30.5 & 0.066 & 33.52 & 33.53 & 0.378 \\
TA & -0.1 & -0.65 & 0.593 & -3.5 & -2.6 & 0.361 & 1.35 & 3.6 & $0.002^{* *}$ \\
HN24 & 0 & 0 & $0.044^{*}$ & 0 & 0 & 0.568 & 0 & 0 & $0.001^{* *}$ \\
HS & 127 & 144 & $0.001^{* *}$ & 123 & 130 & 0.164 & 139 & 156 & $<0.001^{* * *}$ \\
\hline
\end{tabular}

\section{Conclusions}

In this study, through a 2-year field campaign, we analysed the predisposing factors for snow gliding and glide-snow avalanches.

From the data registered in two monitoring seasons at two experimental test sites in Aosta Valley, even if the differences are not significant, we found that cold glide-snow avalanche events occurred with a higher VLWC in the soil and a lower VLWC in the basal snowpack layer than in warm events.

Significant differences were instead found between the predisposing factors during gliding and non-gliding periods, considering the whole dataset together or dividing cold and warm gliding periods. However, no general trend during cold or warm periods was found at the two test sites.

Our analysis on the potential driving factors for gliding processes underlined the importance of soil VLWC, in particular for warm glide events. Though we could not find a clear and generalizable trend, the example of the warm gliding periods in 2014 at the site Pista Nera shows how the glide-snow rate increased exponentially compared to the VLWC in the soil.

In conclusion, among the parameters considered in this study, which sometimes showed contrasting effects, our findings contribute to assessment of the importance of soil water content in snow gliding processes. Therefore, this result supports the need, already suggested by other scientists (e.g. Höller, 2014), of analysing such processes with an interdisciplinary approach which integrates snow and soil science.

An effort which should be made by scientists would be to share all the data collected at the different experimental test sites, in order to create a common rich database and to be able to analyse the driving factors for snow gliding processes, also including site characteristics. Doing so, the results obtained at the different test sites might be generalized.

Data availability. The datasets generated and analysed during the current study are available from the corresponding author upon reasonable request. 
Author contributions. MM and MF designed the study; MM collected data; MM and DG completed the data analysis; BF led the project execution; MM led the writing with revisions and contributions from all authors. All the authors approved the final version.

Competing interests. The authors declare that they have no conflict of interest.

Acknowledgements. The work was developed within the Unità di ricerca "Mountain Risk Research Team" and supported by the NextData-LTER-Mountain project. We would like to thank the Ufficio Neve e Valanghe (Fondazione Montagna sicura) and the Centro Funzionale of the Aosta Valley region for avalanche, snow and weather data. We also thank Laura Dublanc, Elisabetta Ceaglio, Davide Viglietti, Giuseppe Comola, Arnoldo Welf and Monterosa S.p.a. for technical and logistic support at the experimental test sites.

Financial support. This research has been supported by Regione Autonoma Valle d'Aosta (Bando per la creazione e lo sviluppo di Unita di Ricerca, D.G.R. n. 1988, 26/08/2011) and NextData Data-LTER-Mountain Project (protocollo ISAC CNR n. 0000326, 30/01/2014).

Review statement. This paper was edited by Oded Katz and reviewed by Christophe Ancey and one anonymous referee.

\section{References}

Ancey, C. and Bain, V.: Dynamics of glide avalanches and snow gliding, Rev. Geophys., 53, 745-784, https://doi.org/10.1002/2015RG000491, 2015.

ARPA Piemonte (Sistemi Previsionali): Rapporto tecnico mensile Novembre 2014, 2015.

Castebrunet, H., Eckert, N., Giraud, G., Durand, Y., and Morin, S.: Projected changes of snow conditions and avalanche activity in a warming climate: the French Alps over the 20202050 and 2070-2100 periods, The Cryosphere, 8, 1673-1697, https://doi.org/10.5194/tc-8-1673-2014, 2014.

Ceaglio, E., Mitterer, C., Maggioni, M., Ferraris, S., Segor, V., and Freppaz, M.: The role of soil volumetric liquid water content during snow gliding processes, Cold Reg. Sci. Technol., 136, 17-29, https://doi.org/10.1016/j.coldregions.2017.01.007, 2017.

Clarke, J. A. and McClung, D. M.: Full-depth avalanche occurrences caused by snow gliding. Coquihalla, B.C., Canada, J. Glaciol., 45, 539-546, https://doi.org/10.3189/S0022143000001404, 1999.

Dreier, L., Harvey, S., van Herwijnen, A., and Mitterer, C.: Relating meteorological parameters to glide-snow avalanche activity, Cold Reg. Sci. Technol., 128, 57-68, https://doi.org/10.1016/j.coldregions.2016.05.003, 2016.
Feistl, T., Bebi, P., Dreier, L., Hanewinkel, M., and Bartelt, P.: Quantification of basal friction for technical and silvicultural glide-snow avalanche mitigation measures, Nat. Hazards Earth Syst. Sci., 14, 2921-2931, https://doi.org/10.5194/nhess14-2921-2014, 2014.

Fierz, C., Armstrong, R. L., Durand, Y., Etchevers, P., Greene, E., McClung, D. M., Nishimura, K., Satyawali, P. K., and Sokratov, S. A.: The international classification for seasonal snow on the ground. IHP-VII Technical Documents in Hydrology No. 83, IACS Contribution No. 1, UNESCO-IHP, Paris, 2009.

Fromm, R., Baumgärtner, S., Leitinger, G., Tasser, E., and Höller, P.: Determining the drivers for snow gliding, Nat. Hazards Earth Syst. Sci., 18, 1891-1903, https://doi.org/10.5194/nhess18-1891-2018, 2018.

Godio, A., Frigo, B., Chiaia, B., Maggioni, M., Freppaz, M., Ceaglio, E., and Dellavedova, P.: Integration of upward GPR and water content reflectometry to monitor snow properties, Near Surf. Geophys., 16, 1-10, https://doi.org/10.3997/18730604.2017060, 2018.

Hartmann, D. L., Klein Tank, A. M. G., Rusticucci, M., Alexander, L. V., Brönnimann, S., Charabi, Y., Dentener, F. J., Dlugokencky, E. J., Easterling, D. R., Kaplan, A., Soden, B. J., Thorne, P. W., Wild, M., and Zhai, P. M.: Observations: Atmosphere and Surface. In: Climate Change 2013: The Physical Science Basis. Contribution of Working Group I to the Fifth Assessment Report of the Intergovernmental Panel on Climate Change, edited by: Stocker, T. F., Qin, D., Plattner, G.-K., Tignor, M., Allen, S. K., Boschung, J., Nauels, A., Xia, Y., Bex, V., and Midgley, P. M., Cambridge University Press, Cambridge, United Kingdom and New York, NY, U'Sant'Anna", 2013.

Höller, P.: Snow gliding and glide avalanches: a review, Nat. Hazards, 71, 1259-1288, https://doi.org/10.1007/s11069-013-09639, 2014.

In der Gand, H. and Zupancic, M.: Snow gliding and avalanches, IAHS Publ., 69, 230-242, 1966.

Lal, R. and Shukla, M. K.: Principles of Soil Physics. Marcel Dekker Inc., NewYork-U'Sant'Anna”, Basel, CH, 2004.

Leitinger, G., Hoeller, P., Tasser, E., Walde, J. and Tappeiner, U.: Development and validation of a spatial snow-glide model, Ecol. Model., 211, 363-374, https://doi.org/10.1016/j.ecolmodel.2007.09.015, 2008.

Maggioni, M., Godone, D., Höller, P., Oppi, L., Stanchi, S., Frigo, B. and Freppaz, M.: Snow gliding susceptibility: the Monterosa Ski resort, NW Italian Alps, J. Maps, 12, 115-121, https://doi.org/10.1080/17445647.2016.1167785, 2016.

Margueritat, D.: Retour d'observations sur les plaques de reptation, Neige \& Avalanches, 152, 18-22, 2016.

Morán-Tejeda, E., López-Moreno, J. I., Stoffel, M., and Beniston, M.: Rain-on-snow events in Switzerland: Recent observations and projections for the 21st century, Clim. Res., 71, 111-125, https://doi.org/10.3354/cr01435, 2016.

Stanchi, S., Freppaz, M., and Zanini, E.: The influence of Alpine soil properties on shallow movement hazards, investigated through factor analysis, Nat. Hazards Earth Syst. Sci., 12, 18451854, https://doi.org/10.5194/nhess-12-1845-2012, 2012. 